\title{
A Study on the Korean Conversation Speech Level and Spectrum in Sound-Treated Environment
}

\author{
Young Kwon Han', Kyoungwon Lee ${ }^{1,2}$ \\ 'Department of Audiology and Speech-Language Pathology, Hallym University of Graduate Studies, Seoul, Korea \\ ${ }^{2}$ HUGS Center for Hearing and Speech Research, Seoul, Korea
}

Received: March 2, 2020

Revised: March 25, 2020

Accepted: March 27, 2020

Correspondence: Kyoungwon Lee, PhD Department of Audiology and Speech-Language Pathology, Hallym University of Graduate Studies, 427 Yeoksam-ro, Gangnam-gu,

Seoul 06197, Korea

Tel: $+82-2-2051-4951$

Fax: +82-2-3453-6618

E-mail: leekw@hallym.ac.kr
Purpose: Several studies have reported the differences between Korean and other countries' speech in long-term average speech spectrum (LTASS) and band importance function. Authors tried to identify the conversational speech level, the resulting spectrum, and the LTASS for Korean. The purpose of this study was to support the production of a Korean-type hearing aid fitting formula to effectively improve the sound quality of hearing aids and the communication abilities with hearing aids, and to standardize the sound stimuli required to measure the performance of hearing aids. Methods: A total of 73 participants with normal hearing and with no specific voice and language deficits was voluntarily recruited from capital, Gyeongsang and Jeolla areas. The conversational speech level was measured by vocalizing 'soft,' 'moderate,' 'raised,' and 'loud' at a distance of $1.0 \mathrm{~m}$ from the speaker. And LTASS was measured by vocalizing it at a distance of $0.2 \mathrm{~m}$ from the speaker. Results: There was a difference in the mean of males and females in the conversation level, but no significant regional differences were shown. The conversational speech level corresponding to 30th, 65th, and 99th percentiles was 59.67, 64.74, and $79.07 \mathrm{~dB}$ sound pressure level, respectively. And the speech spectrum of 30th, 65th, and 99th percentile and LTASS showed in different forms from the international speech test signal. Conclusion: The results of this study should help to calculate the Korean type hearing aid fitting formula and should be used as the basic data to determine the characteristics of the sound stimuli when measuring the performance of the hearing aid.

Key Words: Conversational speech level, Fitting formula, Korean language, Long-term average speech spectrum, Speech spectrum.

\section{INTRODUCTION}

대화음레벨(conversational speech level)이란 서로 마주하 여 이야기를 주고받을 때 나타나는 어음의 음압레벨(sound pressure level, SPL), 장기평균어음스펙트럼(long-term average speech spectrum, LTASS)은 특정 기간(시간) 동안의 1 또 는 $1 / 3$ 옥타브 주파수에서 평균 SPL 또는 이득을 의미하며, 이 는 평균화된 어음의 정보를 제공한다. 청각학에서의 대화음레 벨과 LTASS는 주로 난청인이 착용하는 보청기의 이득 산출 또는 보청기의 전기음향적 조절(Byrne \& Dillon, 1986; Byrne et al., 2001; Cornelisse et al., 1995; Lee \& Kim, 2011), 보청기 의 성능 측정(IEC, 2005; 2012) 등에 사용한다.

(c) This is an Open Access article distributed under the terms of the Creative Commons Attribution Non-Commercial License (https://creativecommons.org/licenses/by-nc/4.0) which permits unrestricted non-commercial use, distribution, and reproduction in any medium, provided the original work is properly cited. 청력역치레벨(hearing threshold level)에 따른 보청기의 이 득을 산출하기 위해서는 보청기적합공식(hearing aid fitting formula)을 이용하는 것이 효과적이다. 보청기적합공식에서 대 화음레벨 그리고 LTASS를 이용한 비선형의 보청기적합공식을 개발한 해외의 사례를 살펴보면 National Acoustic Laboratories' nonlinear fitting procedure, version 1(NAL-NL1; National Acoustic Laboratories, Chatswood, Australia)은 1/2 옥타브 주파수에서 Byrne et al.(1994)의 LTASS를 기준으로 입력 SPL에 대한 이득량을 계산하였다(Byrne et al., 2001). 그리고 the desired sensation level input/output (DSL I/O) (Scollie et al., 2005)은 쾌적강도레벨(most comfortable level), 불쾌강도레벨(uncomfortable level), 그리고 LTASS를 고려하 여 보청기적합공식을 도출하였으며, 또한 유아, 어린이 및 성인 의 최신 보청기 사용을 위한 version 개정을 위해 Pearsons et al.(1977)의 연구를 참고하였다. 한국 연구의 경우 $\mathrm{Hallym} \mathrm{Au}-$ 
diology Institute-version 1(Jin et al., 2017)은 보청기적합공식 개발 시 한국어의 LTASS와 대역중요함수(band importance function), 역동 범위(dynamic range)와 같은 언어의 음향 및 언어적 특성을 고려하였으며, Lee \& Kim(2011)은 대화음레벨 과 음량 범주 위치 확인 시, 한국어음의 평균 SPL, LTASS 및 청력역치레벨에 따른 쾌적강도레벨의 변화를 통해 이득을 계 산하였다.

보청기의 성능 측정 시 대화음레벨과 LTASS의 활용 사례를 살펴보면 국제전기기술위원회(International Electrotechnical Commission, IEC)에서는 보청기의 이득 측정 시 30, 65, 99 퍼 센타일(percentile)에 대한 대화음레벨과 이에 따른 어음스펙트 럼을 이용한다(IEC, 2012). Holube et al.(2010)은 성능 측정의 표준화를 위해 Byrne et al.(1994)의 연구 방법을 바탕으로 다 양한 국가의 어음 표준화를 시도하여 국제어음시험신호(international speech test signal, ISTS)를 개발하였다.

대화음레벨 및 LTASS에 대한 연구를 살펴보면 대화음레벨 은 Pearsons et al.(1977)이 실제 대화 시 소음 상황에서 대화가 적절하게 가능한지를 확인하기 위해 다양한 상황에서 배경소음 및 대화음레벨을 $1.0 \mathrm{~m}$ 에서 녹음 및 분석하였다. 그중 무반향실 측정에서는 가벼운(casual), 보통의(normal), 조금 큰(raised), 큰 (loud), 그리고 외치는(shout) 5 개 범주를 사용하였으며, 연구 결 과 가벼운 대화음레벨과 큰 대화음레벨 간에는 대략 $30 \mathrm{~dB}$ $\mathrm{SPL}$ 의 차이가 나타났지만 5 개의 각 범주 간의 차이는 5 에서 12 $\mathrm{dB}$ SPL까지 다양하게 나타났다. 또한 NAL-NL1, DSL I/O 보 청기적합공식 도출 시 사용된 LTASS는 Byrne et al.(1994)이 언 어에 따른 보청기의 이득 산출 등에 사용하기 위해 13 개의 언어 (영어, 스웨덴어, 덴마크어, 독일어, 프랑스어, 일본어, 광둥어, 표 준 중국어, 러시아어, 웨일스어, 스리랑카어, 베트남어, 아랍어) 를 $0.2 \mathrm{~m}$ 거리에서 녹음한 후 LTASS를 분석하였다. 분석 결과 $4,000 \mathrm{~Hz}$ 이상에서 각 국가 언어의 강도에 차이가 나타났지만 그 차이는 무시할 수 있다고 하였다. 그러나 상기의 연구에서는 한국어의 LTASS를 확인할 수 없었다. 이에 따라 Jin \& Lee(2010)는 Byrne et al.(1994)이 보고한 LTASS의 보편성의 여 부를 검증하고자 하였으나 결과적으로 한국어와 영어의 LTASS 특성이 크게 다르지 않음을 확인하였다. 하지만 Byrne et al.(1994)의 연구와 비교해 상대적으로 화자 어음 수가 적어 지속적인 자료 수집을 통해 화자 성별 및 화자 연령에 따른 LTASS의 비교 연구가 이루어져야 한다고 보고하였으며, $\mathrm{Mo}^{-}$ radi et al.(2014)의 연구 또한 화자 성별에 따른 LTASS를 확인 하기 위해서는 더 많은 대상자 수가 필요하다고 보고하였다. 그 러나 Lee et al.(2008)과 Noh \& Lee(2012) 연구에서는 한국어 의 LTASS와 영어음의 LTASS의 차이가 나타난다고 보고하였 으며, Jin et al.(2016) 연구에서는 영어와 한국어의 대역중요함수
에서 한국어의 역동 범위가 저주파수에서 영어의 역동 범위보 다 좁다는 의견을 제시하였다.

상기의 연구를 종합해 보면 특정 국가에서 사용하는 보청기 의 전기음향적 조절 그리고 성능 측정을 위해서는 해당 국가 언어의 대화음레벨 및 LTASS를 확인하는 것은 매우 중요하다. 현재 한국의 경우에는 대부분 유럽, 미국, 호주 등의 영어권에 서 개발한 보청기와 보청기적합 소프트웨어를 수입하여 사용 하고 있다. 이에 따라 Lee \& Kim(2009)은 서구에서 개발한 보 청기적합공식을 사용하는 경우 한국 난청인의 심리음향 및 언 어적인 특성에 맞지 않아 한국 난청인이 사용하는 보청기의 전 기음향 조절에 지장을 초래할 수 있다고 하였다.

이에 본 연구에서는 한국어를 모국어로 하는 건청 성인 남녀 의 발성 방법에 따른 대화음레벨과 LTASS를 방음실 환경에서 확인하고자 하였다. 구체적인 내용은 첫째, $30,65,99$ 퍼센타일 에 해당하는 대화음레벨과 이에 따른 스펙트럼을 확인하고자 하였다. 둘째, 보통 크기로 발성한 한국어음에 대한 LTASS를 확인하고자 하였다. 한국어 대화음레벨과 스펙트럼 그리고 LTASS의 확인을 통하여 한국 난청인이 착용하는 보청기의 음 질 및 의사소통능력을 효과적으로 개선하기 위한 보청기적합 공식의 산출과 보청기의 성능 측정에 필요한 신호음의 표준화 에 도움을 주고자 하였다.

\section{MATERIALS AND METHODS}

\section{연구 대상}

대화음레벨과 LTASS를 확인하기 위한 대상자는 한국어를 모국어로 사용하는 한국인으로 평균 연령 25.9세(표준편차: 7.27 세)의 성인 73명(남자 25명, 여자 48명)이었다. 대상자는 육 안 관찰 시 외이도 및 고막에 이상소견이 없고 한국어판 음성 장애지수(Yun, 2007)를 통해 음성 및 언어적 특이사항이 없으 며, 순음기도청력검사에서 0.25 에서 $8.0 \mathrm{kHz}$ 의 청력역치레벨이 $25 \mathrm{~dB} \mathrm{HL}$ 이하, 단어인지도는 $45 \mathrm{~dB}$ HL에서 $90 \%$ 이상인 피검 자를 대상으로 하였다. 그리고 대상자는 수도권 15명, 경상도 36 명 및 전라도 22 명으로 총 73 명을 모집하였다.

\section{모집단의 산출 근거}

본 연구에 필요한 최소 표본의 수를 알아내기 위해 20명의 예비실험 데이터를 추출하여 아래의 식(Scheaffer et al., 2012) 으로 계산하였다.

$$
\mathrm{n}=\frac{\mathrm{NZ}_{\alpha / 2}^{2} \mathrm{~S}^{2}}{\mathrm{Nd}^{2}+\mathrm{Z}_{\alpha / 2}^{2} \mathrm{~S}^{2}}
$$

[Equation 1]

상기의 식에서 신뢰도 $100(1-\alpha) \%$ 일 때, $\mathrm{n}$ 은 필요한 표본의 
Table 1. Mean (standard deviation) of conversational speech sound pressure level according to vocalization methods

\begin{tabular}{lccccc}
\hline \multirow{2}{*}{ Gender } & \multicolumn{5}{c}{ Conversational sound pressure level in dB } \\
\cline { 2 - 6 } & Soft & Moderate & Raised & Loud & Overall \\
\hline Female & $56.81(2.81)$ & $60.23(2.87)$ & $63.62(3.09)$ & $68.90(4.67)$ & $61.03(5.27)$ \\
Male & $58.98(2.50)$ & $61.74(2.62)$ & $64.49(3.04)$ & $69.31(4.12)$ & $64.72(4.98)$ \\
Overall (range) & $57.55(2.88)$ & $60.75(2.86)$ & $64.22(3.06)$ & $69.18(4.27)$ & $62.93(5.44)$ \\
& $(50.7-65.8)$ & $(53.3-67.3)$ & $(57.8-70.8)$ & $(60.6-81.3)$ & \\
\hline
\end{tabular}

크기, $\mathrm{N}$ 은 모집단의 크기, $\mathrm{s}$ 는 표준편차, $\mathrm{d}$ 는 오차한계이며 $\mathrm{z}_{\alpha}$ 는 표준 정규분포의 제100(1- $\alpha)$ 번째 퍼센타일이다. 예비실험 데이 터 분석으로 얻은 표준편차 $\mathrm{s}=2.84$ 를 20 세 이상 인구를 모집 단으로 할 때, 모집단 크기 $\mathrm{N}=36,765,374$ 명(KOSIS, 2019), 오 차한계 $\mathrm{d}=0.7(\mathrm{~dB})$, 신뢰도 $95 \%$ 에서 $\mathrm{z}_{0.025}=2$ 를 사용하여 계산 하면 필요한 최소 표본 수(n)는 65.84로 나타났다(Equation 1 참조). 이에 근거하여 본 연구에서는 총 73 명에 대한 피검자의 데이터를 구하였다.

\section{연구 장비}

외이도 및 고막의 이상 유무는 이경 검사기 $\mathrm{MD} \mathrm{SCOPE}$ MS101(MD SCOPE, New Taipei, Taiwan), 음성 및 언어적 특 이사항 확인은 한국어판 음성장애지수(Yun, 2007)를 사용하 였다. 순음 및 어음청각검사는 GSI AudioStar Pro (Grason Stadler Inc., Eden Prairie, MN, USA), GSI 61(Grason Stadler Inc.), 그리고 헤드폰은 모두 TDH-49(Telephonics, Farmingdale, NY, USA)를 사용하였으며, 단어인지도검사는 한국 표준 단음절어표(Korean standard monosyllabic word lists)를 사용 하였다. 대화음레벨 및 LTASS는 A 가중치로 1 분간 측정했을 때 $30 \mathrm{~dB} \mathrm{~L}_{\mathrm{Aeq}}$ 이하의 소음레벨이 나타나는 방음실(남부대학 교, 부산가톨릭대학교, 한림국제대학원대학교)에서 측정하였으 며, 읽기 자료는 읽기 쉬우며 반복 구절이 없고, 대화 문장이 많 은 한국 전래 동화책『한글학교 학생용 동화로 배우는 한국어 (Overseas Korean Education Promotion Foundation, 2006)』 를 선택하였다. 대화음레벨 측정은 소음계 Hand-held analyzer type 2250-L (Brüel \& Kjær, Nærum, Denmark)로 실험 전 에 한국표준과학연구원에서 교정을 마친 후 사용하였다.

\section{연구 절차}

\section{대상자의 배치}

대화음레벨과 어음스펙트럼 측정은 Byrne et al.(1994)과 그 리고 Peasrons et al.(1977)이 사용한 방법을 이용하였다. 대상 자의 배치는 첫째, 대상자를 의자에 앉힌 후 읽기 자료를 소음 계와 화자의 입보다 최대한 아래에 위치하도록 들게 하였으며, 소음계는 입의 수평면 아래 $45^{\circ}$ 에 배치하였다. 이때 입과 소음
Table 2. The results of 3-way analysis of variance for conversational speech sound pressure level according to the vocalization method of male and female speakers in each area

\begin{tabular}{lrr}
\hline \multicolumn{1}{c}{ Main effects } & \multicolumn{1}{c}{ F } & $p$-value \\
\hline Gender (male, female) & 8.110 & 0.005 \\
Area (metropolitan area, Gyeongsang, Jeolla) & 1.609 & 0.202 \\
Vocalization method (soft, moderate, raised, loud) & 140.264 & $<0.001$ \\
\hline
\end{tabular}

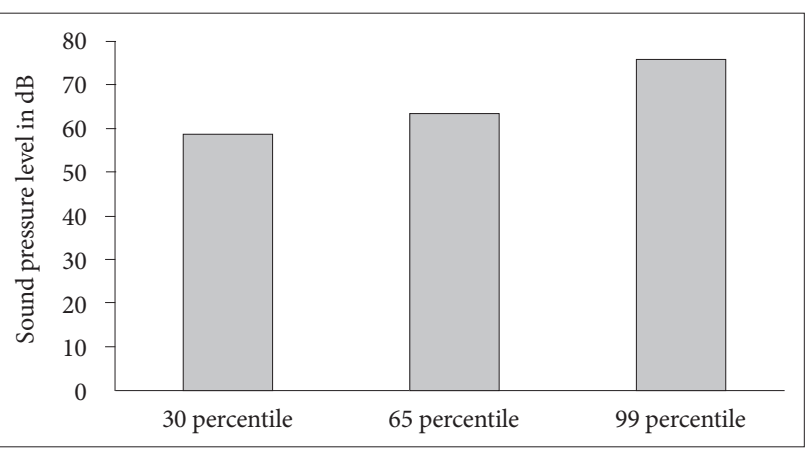

Figure 1. Sound pressure level $(\mathrm{dB})$ of 30 th, 65 th, 99th percentile for Korean conversational speech level.

계의 거리는 $1.0 \mathrm{~m}$ 를 유지하도록 하였다. 둘째, LTASS는 Byrne et al.(1994)의 방법을 이용하였다. 대상자를 의자에 앉힌 후 소음계를 입의 수평면 아래 $45^{\circ}$ 에 배치하였으며, 입과 소음 계의 거리는 $0.2 \mathrm{~m}$ 였으며, 읽기 자료는 $1.0 \mathrm{~m}$ 방법과 마찬가지 로 대상자가 들게 하였다.

\section{대화음레벨과 LTASS의 측정}

대화음레벨과 $30,65,99$ 퍼센타일에 대한 어음스펙트럼 측정은 첫째, 대상자에게 연구 목적과 실험 방법을 설명한 후 동화책의 여러 내용 중 대상자가 읽을 동화책 내용 하나를 선 택하게 하였다. 둘째, 대상자의 목을 풀고 자연스러운 발성을 위해 동화책 내의 2 문장 이상을 읽게 하였다. 셋째, 책을 읽 는 도중 틀린 단어가 있어도 수정하지 않고 계속 읽을 것을 지시하였으며, 대상자가 생각하는 일상적인 대화할 때의 크 기를 기준으로 '작게', '보통', '조금 크게', '크게' 순으로 발성하 게 하여 측정하였다. 넷째, LTASS는 대화음레벨과 어음스펙 트럼 측정 방법과 동일하지만, 대상자가 생각하는 일상적인 대화를 할 때처럼 '보통 크기'로만 발성하게 하여 측정하였다. 대화음레벨과 LTASS는 총(total) SPL 및 1/3 옥타브 주파수 
에서 $\mathrm{L}_{\mathrm{Zeq}}(\mathrm{dB} \mathrm{SPL})$ 로 측정하였다.

\section{결과 분석}

성별, 지역별, 발성 방법에 따른 차이는 상호작용을 포함하여
삼원배치 분산분석모형으로 분석한 결과 2차 이상의 상호작용 은 유의하지 않을 경우 상호작용은 모두 오차 항으로 풀링 (pooling)하여 주 효과만 포함된 삼원배치 분산분석을 사용하 였다. 어음스펙트럼은 $1 / 3$ 옥타브 주파수에서 $30,65,99$ 퍼센

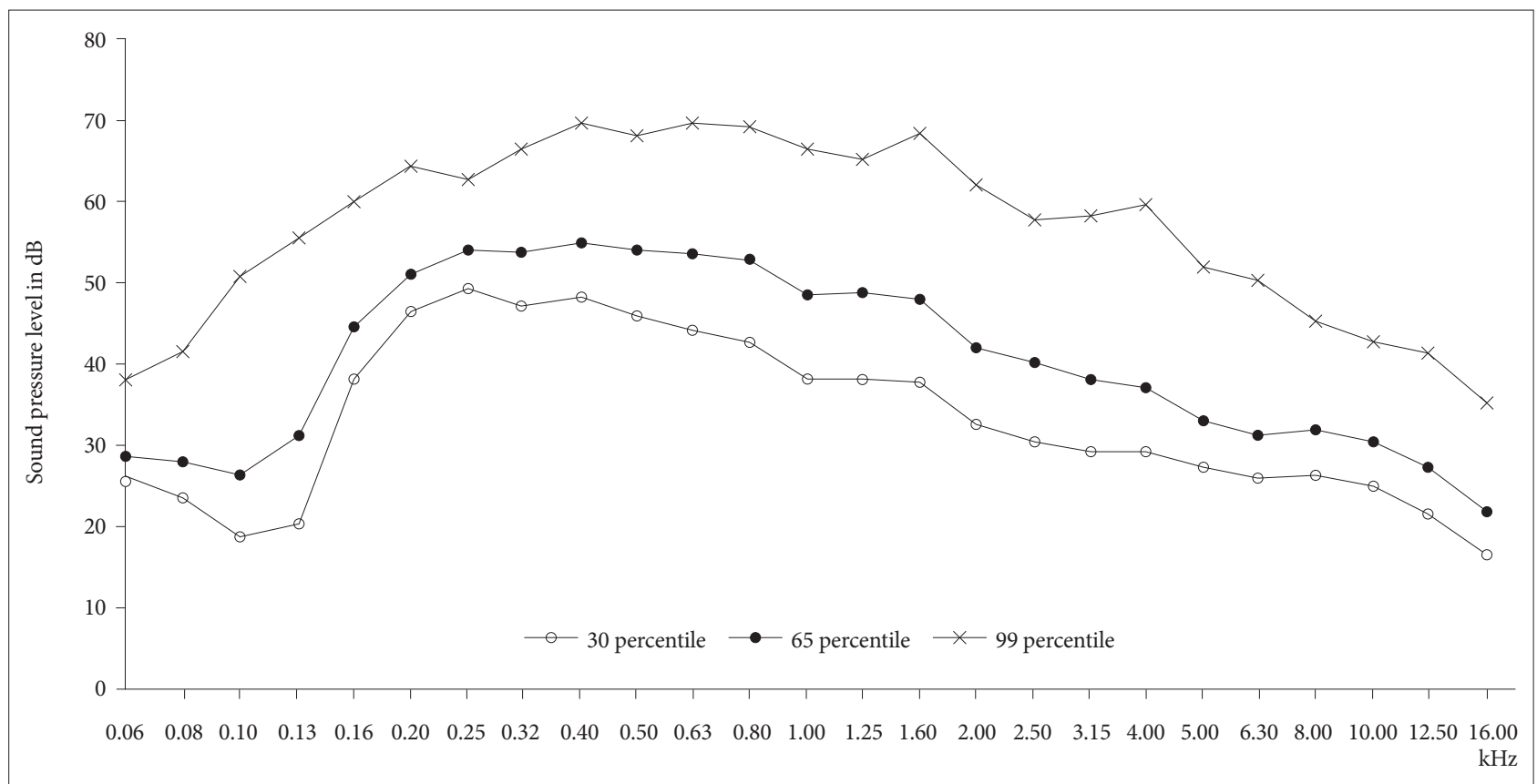

Figure 2. 30th, 65th, 99th percentile at one-third-octave bands.

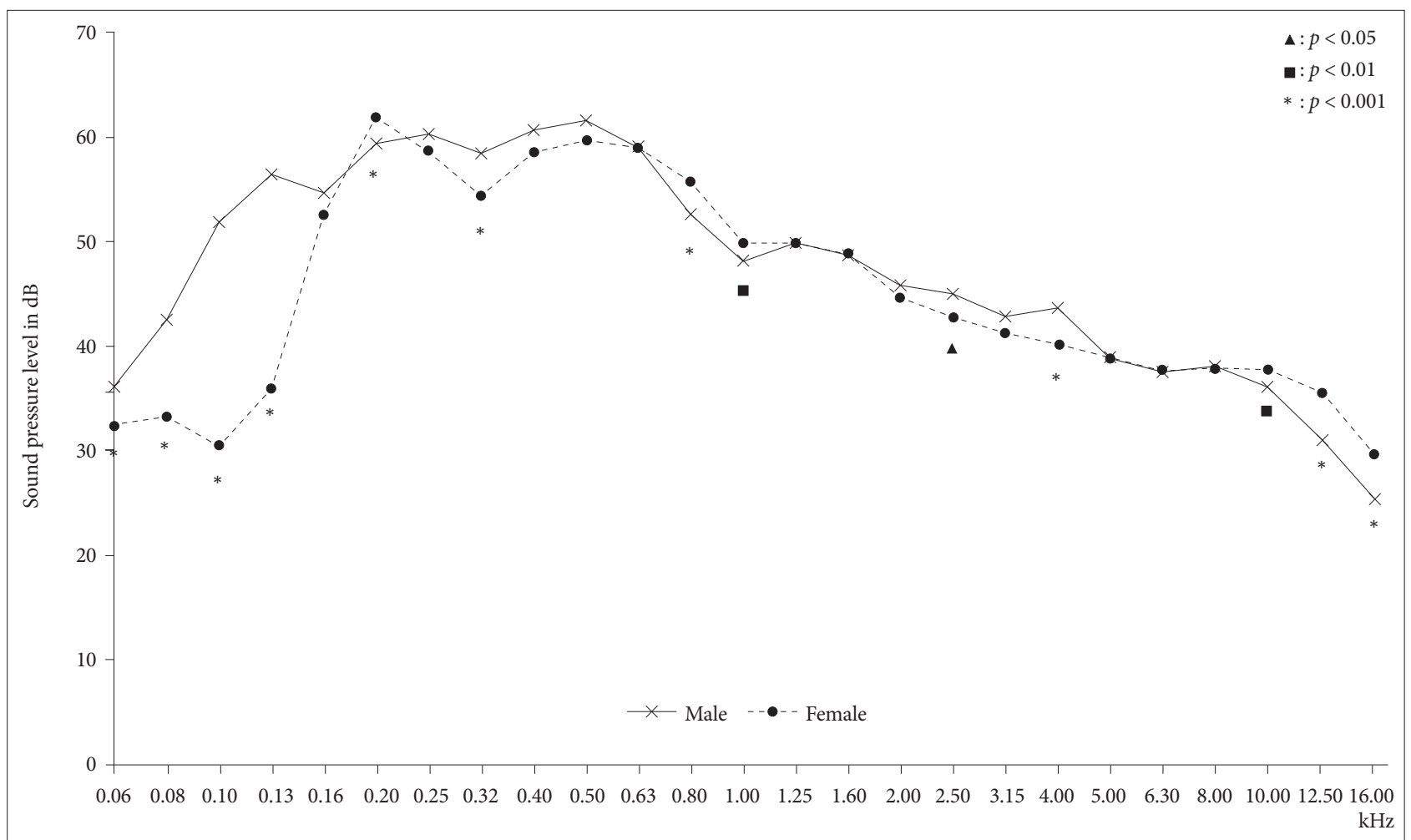

Figure 3. Long-term average speech spectrum at one-third-octave bands. 
타일에 해당하는 SPL 및 어음스펙트럼을 구하였다. '보통' 크기 로 발성한 남녀 LTASS의 차이는 독립표본 $t$-검정(independent $t$-test)을 통해 확인하였다. 본 연구의 통계 분석은 SPSS Version 25(IBM Corp., Armonk, NY, USA)를 사용하였다.

\section{RESULTS}

본 연구에서는 한국형 보청기적합공식의 산출, 효과적인 보 청기의 조절을 위해 경기도를 포함한 서울, 경상도 및 전라도에 거주하는 남녀 화자가 $1.0 \mathrm{~m}$ 의 거리에서 발성하는 방법('작게', '보통', '조금 크게', ‘크게')에 따른 각각의 대화음레벨 그리고 30, 65, 99 퍼센타일에 해당하는 대화음레벨 및 어음스펙트럼을 확 인하였다. 그리고 성능 측정에 필요한 신호음의 표준화에 도움 을 주기 $0.2 \mathrm{~m}$ 거리에서 '보통' 크기로 발성하는 한국어음의 LTASS를 확인하였다.

\section{대화음레벨과 어음스펙트럼}

\section{대화음레벨}

성별, 지역별, 발성 방법에 따른 대화음레벨의 차이를 분석해 본 결과, 성인 남성의 평균 대화음레벨은 여성의 평균 대화음레 벨보다 $3.69 \mathrm{~dB}$ 높았으며 $(t=6.16, p<0.001)$, 서울과 경기, 경 상, 전라 지역별 대화음레벨의 평균(표준편차)은 각각 63.62 (5.39), 62.93(5.42), 62.45(5.52) dB SPL로 통계적으로 유의미한 차이는 없었다 $(\mathrm{F}=0.832 ; p=0.436)$. 성인 남녀가 $1.0 \mathrm{~m}$ 에서 '작게', '보통', '조금 크게’ 및 ‘크게' 발성할 때 통계적으로 유의한 차이가 나타났다 $(\mathrm{F}=164.15, p<0.000)$. Table 1에 유의한 차 이가 있는 성별 및 발성 방법별 평균(표준편차)을 요약하였다.

성별, 지역별, 발성 방법에 따른 차이를 상호작용(interaction)을 포함하여 삼원배치 분산분석모형으로 분석한 결과 2차 이상의 상호작용은 유의하지 않았으므로[지역 $\times$ 발성 방법 $(p=$ $0.737)$, 지역 $\times$ 성별 $(p=0.070)$, 성별 $\times$ 발성 방법 $(p=0.859)$, 성 별 $\times$ 지역 $\times$ 발성 방법 $(p=0.906)]$ 상호작용은 모두 오차 항 으로 풀링하여 주 효과만 포함된 삼원배치 분산분석을 사용하 였다. 분석결과는 Table 2 와 같이 성별 및 발성 방법에 따른 차 이는 유의하였으나 지역에 따른 차이는 유의하지 않았다.

\section{$30,65,99$ 퍼센타일의 대화음레벨과 어음스펙트럼}

$\operatorname{IEC}(2012)$ 에서 제시한 30, 65, 99 퍼센타일, 즉 한국어 대화 음의 '작은, '보통', '큰' 대화음레벨은 각각 $59.67,64.74,79.07$ $\mathrm{dB}$ SPL로 나타났다(Figure 1).

그리고 Figure 2에 IEC(2012)에서 제시한 것과 마찬가지로 여성 대화음레벨의 $30,65,99$ 퍼센타일에 해당하는 SPL을
$0.06 \mathrm{kHz}$ 에서 $16.0 \mathrm{kHz}$ 의 주파수 범위에서 나타내었다. Figure 2에서 30, 65, 99 퍼센타일의 스펙트럼은 $0.25 \mathrm{kHz}$ 에서 $0.40 \mathrm{kHz}$ 사이에서 최대치를 나타냈으며, 최대치를 기준으로 주파수가 낮아지거나 높아질수록 SPL이 감소하는 형태를 나 타내었다.
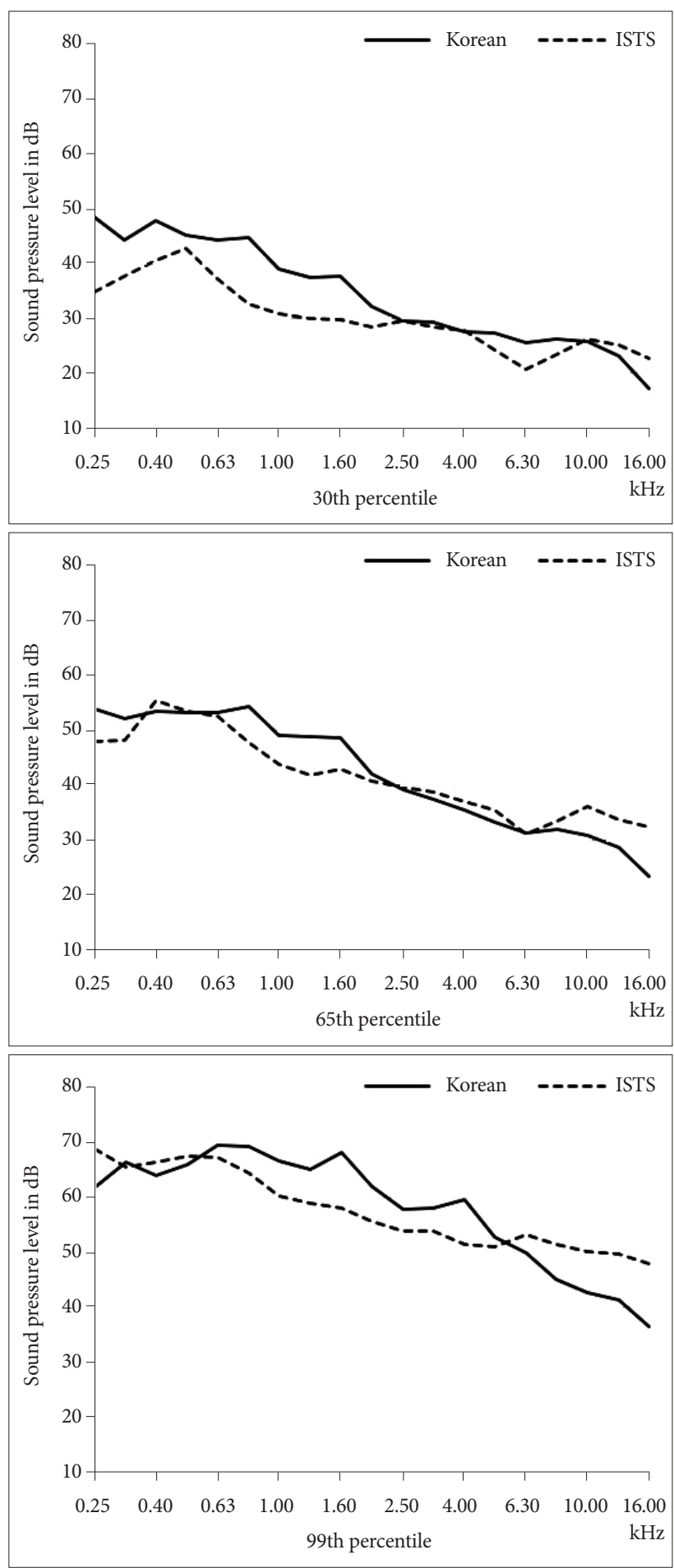

Figure 4. Comparison of spectrum between Korean and ISTS by female speakers. ISTS: international speech test signal. 
Table 3. One-sample $t$-test results of the Korean and English long-term average speech spectrum at one-third octave frequencies

\begin{tabular}{lccccccccccc}
\hline Frequency $(\mathrm{kHz})$ & 0.25 & 0.32 & 0.40 & 0.50 & 0.63 & 0.80 & 1.00 & 1.25 & 1.60 & 2.00 \\
\hline Korean & 59.1 & 55.5 & 60.0 & 60.7 & 59.9 & 56.9 & 50.4 & 49.8 & 49.5 & 45.0 \\
ISTS & 55.9 & 53.1 & 56.7 & 56.7 & 55.4 & 53.0 & 49.3 & 47.3 & 46.7 & 43.8 \\
$p$-value & $<0.001$ & 0.002 & $<0.001$ & $<0.001$ & $<0.001$ & $<0.001$ & 0.114 & 0.004 & $<0.001$ & 0.084 \\
\hline Frequency $(\mathrm{kHz})$ & 2.50 & 3.15 & 4.00 & 5.00 & 6.30 & 8,00 & 10.00 & 12.50 & 16.00 & - \\
\hline Korean & 43.0 & 41.8 & 40.5 & 39.1 & 38.1 & 37.8 & 37.5 & 35.2 & 29.1 & - \\
ISTS & 42.3 & 41.7 & 40.3 & 39.6 & 40.2 & 39.9 & 40.0 & 37.8 & 36.1 & - \\
$p$-value & 0.188 & 0.865 & 0.605 & 0.885 & 0.005 & 0.014 & 0.022 & 0.017 & $<0.001$ & - \\
\hline
\end{tabular}

ISTS: international speech test signal

\section{LTASS}

Figure 3에 성인 남녀 및 평균 LTASS를 나타내었다. 그림에 서 $0.06,0.08,0.10,0.13,0.25,0.32,0.40 \mathrm{kHz}$ 에서는 남성의 SPL이, $0.20,0.80,10.00,12.50,16.00 \mathrm{kHz}$ 에서는 여성의 SPL 이 높게 나타났다. 최소 및 최대 표준편차는 남성이 4.61과 9.19, 여성이 3.07과 7.71로 각각 나타났다.

\section{DISCUSSIONS}

\section{대화음레벨과 어음스펙트럼}

$\operatorname{IEC}(2005 ; 2012)$ 에서는 보통 크기의 대화음레벨을 $65 \mathrm{~dB}$ SPL로 명시하고 있다. 이에 따라 IEC(2012)에서는 보청기의 성 능 측정, 실이 측정 시 '보통 크기'에 대한 어음을 제시할 때 65 퍼센타일에 해당하는 ISTS의 스펙트럼을 제시하도록 규정하고 있다. 본 연구에서 한국인이 $1.0 \mathrm{~m}$ 거리에서 발성하는 대화음 레벨에서 '보통 크기’로 발성하는 평균 대화음레벨은 60.75(표 준편차, 3.06) dB SPL로 나타났으나 '작게', '보통', '조금 크게' 및 ‘크게’ 발성할 때 65 퍼센타일은 64.74 dB SPL로 IEC(2005; 2012)와 비슷한 수치를 나타냈다.

대화음레벨의 범위를 IEC(2012)에서는 30 퍼센타일인 $55 \mathrm{~dB}$ 에서 99 퍼센타일인 $80 \mathrm{~dB}$ SPL로 정하여 보청기의 성능 측정 및 보청기의 조절에 이용하고 있다. 그러나 본 연구에서 한국어 대화음레벨의 30 퍼센타일과 99 퍼센타일의 각각 $59.67 \mathrm{~dB}$, $79.07 \mathrm{~dB}$ SPL로 나타나 한국어의 30 퍼센타일은 IEC(2012)에 비해 $4.67 \mathrm{~dB}$ 이 더 높게 나타났다. 이러한 차이는 비선형 증폭 시스템에서의 압축역치(compression threshold)의 설정 등 보 청기적합공식의 산출에 영향을 줄 수 있다.

Figure 4에서 여성이 녹음한 한국어와 IEC(2012)에서 제시 한 ISTS의 30, 65, 99 퍼센타일에 대한 스펙트럼을 $0.25 \mathrm{kHz}$ 에 서 $16.00 \mathrm{kHz}$ 까지 비교해 보았다. 어음스펙트럼 역시 30 퍼센 타일에서 많은 차이를 나타냈는데, 특히 에너지가 강한 0.25 $\mathrm{kHz}$ 이하에서 많은 차이를 나타냈다. 그리고 65와 99 퍼센타 일에서도 많은 주파수에서 어음스펙트럼의 차이를 나타냈다.
각 퍼센타일에 대한 어음스펙트럼의 차이 또한 비선형 증폭기 의 압축역치, 압축비율 등 보청기적합공식의 산출, 보청기의 성 능 측정에 필요한 신호음의 제시 $\mathrm{SPL}$, 스펙트럼 등의 특성에 영향을 줄 것으로 보인다.

한국 남녀가 발성하는 대화 음레벨에서 '보통 크기'로 발성했 을 때 평균 대화음레벨은 $61.74 \mathrm{~dB}$ SPL과 $60.23 \mathrm{~dB}$ SPL로 차 이가 나타나지 않았다. 그러나 발성 방법에 따른 전체 평균에서 는 남성이 $64.72 \mathrm{~dB}$ SPL, 여성이 $61.03 \mathrm{~dB}$ SPL로 남성이 여성 에 비해 $3.69 \mathrm{~dB}$ 이 높게 나타났다. 남성의 평균 대화음레벨이 더 높게 나타난 것은 폐활량이 더 큰 남성이 큰 소리로 발성했 을 때의 대화음레벨이 높게 나타났기 때문인 것으로 보인다.

\section{LTASS}

한국 남녀가 $0.2 \mathrm{~m}$ 에서 '보통 크기'로 발성했을 때의 LTASS 에서 남성은 $0.13 \mathrm{kHz}$ 이하의 주파수에서 여성에 비해 SPL이 높게 나타나 Byrne et al.(1994), Noh \& Lee(2012)의 연구와 일 치성을 나타냈다. 그리고 한국 여성의 LTASS는 $0.25 \mathrm{kHz}$ 에서 $16.0 \mathrm{kHz}$ 까지의 주파수 범위에서 $\operatorname{IEC}(2012)$ 에서 제시한 형태 와 다르게 나타났다. Table 3에서 한국어의 평균 LTASS를 ISTS와 일표본 $t$-검정을 통해 확인했을 때 $1.00,2.00,2.50$, $3.15,4.00,5.00,6.30 \mathrm{kHz}$ 를 제외한 모든 $1 / 3$ 옥타브 주파수에 서 차이가 나타났다 $(p<0.05)$ IEC(2012)에서는 ISTS 개발 시 Byrne et al.(1994)의 연구 결과를 국제 LTASS를 기준으로 여 과(filtering)하여 ISTS와 LTASS 차이를 $1 \mathrm{~dB}$ 미만으로 제한 하고 여과한 데이터를 음절 단위로 분절하여 SPL을 산출하는 과정을 거쳤다(Holube, 2010). 따라서 IEC(2012)에서 명시한 ISTS는 본 연구와의 직접적인 비교에서 한계가 있음에도 불구 하고 한국어음의 특성을 반영하지 못하는 것으로 볼 수 있다.

$1.0 \mathrm{~m}$ 에서 발화한 한국인의 대화음레벨에서 30, 65, 99 퍼센 타일은 59.67, 64.74, 79.07 dB SPL로 나타나 30 퍼센타일에 해 당하는 대화음레벨은 IEC(2012)에서 제시한 $55 \mathrm{~dB}$ SPL과 차 이가 있음을 확인하였다. 그리고 한국어 $30,65,99$ 퍼센타일의 어음스펙트럼과 LTASS의 형태 또한 IEC(2012)와 차이가 있음 
을 확인하였다. 이 결과는 향후 한국 난청인이 착용하는 보청 기의 음질 및 의사소통능력의 개선을 위한 보청기적합공식의 산출, 보청기 성능 측정을 위한 신호음의 표준화에 도움을 줄 수 있을 것으로 생각한다.

향후의 연구에서는 소음이 존재하는 다양한 상황에서의 실 제 대화음레벨 및 어음스펙트럼을 체계적으로 측정하여 분석 한다면 난청인의 보청기적합 및 신호음의 표준화에 보다 유용 한 자료로 사용할 수 있을 것이다.

중심 단어 : 대화음레벨·적합공식·한국어 · 장기평균어음스펙트럼·어음스펙트럼.

\section{Ethical Statement}

This study was approved by the Institutional Review Board of Hallym University of Graduate Studies (IRB \# HUGSAUD 631278).

\section{Acknowledgments}

Thanks to participants Catholic University of Pusan, Hallym University of Graduate Studies Nambu University for cooperation in data collection.

\section{Declaration of Conflicting Interests}

There are no conflict of interests.

\section{Funding}

This research was completed while being supported by National Research Foundation of Korea (2018R1A2B6001986).

\section{Author Contributions}

K.L. designed experimental procedures. Y.H. collected and analyzed data. Y.H. and K.L. wrote the paper. Y.H. and K.L. discussed the results together and implications at each data.

\section{ORCID iDs} Kyoungwon Lee
Young Kwon Han https://orcid.org/0000-0002-5878-2637 https://orcid.org/0000-0002-1297-6436

\section{REFERENCES}

Byrne, D. \& Dillon, H. (1986). The National Acoustic Laboratories' (NAL) new procedure for selecting the gain and frequency response of a hearing aid. Ear and Hearing, 7(4), 257-265.

Byrne, D., Dillon, H., Tran, K., Arlinger, S., Wilbraham, K., Cox, R., et al. (1994). An international comparison of long-term average speech spectra. The Journal of the Acoustical Society of America, 96(4), 21082120.

Byrne, D., Dillon, H., Ching, T., Katsch, R., \& Keidser, G. (2001). NALNL1 procedure for fitting nonlinear hearing aids: Characteristics and comparisons with other procedures. Journal of the American Academy of Audiology, 12(1), 37-51.

Cornelisse, L. E., Seewald, R. C., \& Jamieson, D. G. (1995). The input/out- put formula: A theoretical approach to the fitting of personal amplification devices. The Journal of the Acoustical Society of America, 97(3), 1854-1864.

Holube, I., Fredelake, S., Vlaming, M., \& Kollmeier, B. (2010). Development and analysis of an international speech test signal (ISTS). International Journal of Audiology, 49(12), 891-903.

IEC. (2005). IEC 60118-7:2005. Electroacoustics-Hearing Aids-Part 7: Measurement of the Performance Characteristics of Hearing Aids for Production, Supply and Delivery Quality Assurance Purposes. Geneva: International Electrotechnical Commission.

IEC. (2012). IEC 60118-15:2012. Electroacoustics-Hearing Aids-Part 15: Methods for Characterising Signal Processing in Hearing Aids with a Speech-Like Signal. Geneva: International Electrotechnical Commission.

Jin, I. K. \& Lee, J. H. (2010). A comparison of long-term average speech spectrum (LTASS) among Korean monosllyabic words, sentences, and English sentences. Audiology, 6(2), 164-172.

Jin, I. K., Lee, J., Lee, K., Kim, J., Kim, D., Sohn, J., et al. (2016). The bandimportance function for the Korean standard sentence lists for adults. Journal of Audiology and Otology, 20(2), 80-84.

Jin, I. K., Lee, K., Kim, J., Kim, D., Sohn, J., \& Lee, J. (2017). Comparison of a hearing aid fitting formula based on Korean acoustic characteristics and existing fitting formulae. Audiology and Speech Research, 13(3), 216-221.

KOSIS. (2019). Total population (based on the total population housing survey_domestic) ('18). Korean Statistical Information Service (KOSIS). Retrieved from http://kosis.kr/conts/nsportalStats/nsportalStats_0102Body.jsp?menuId=10\&NUM=1007\&searchKeyword=\&fre $\mathrm{q}=\& \mathrm{cnt}$ Update $=\mathrm{Y}$.

Lee, K. W. \& Kim, J. S. (2009). Review in hearing aid prescription methods and its considerations in Korean studies. Audiology, 5(1), 6-12.

Lee, K. W. \& Kim, J. S. (2011). Suggestion of hearing aid gain for Korean hearing impaired (HAG-K). Audiology, 7(2), 119-123.

Lee, K. W., Lee, J. H., \& Lee, J. (2008). Suggestions of multi-talker babble noise using Korean speech sound. Audiology, 4(1), 24-27.

Moradi, N., Maroufi, N., Bijankhan, M., Nik, T. H., Salavati, M., Jalayer, T., et al. (2014). Long-term average spectra of adult Iranian speakers' voice. Journal of Voice, 28(3), 305-310.

Noh, H. \& Lee, D. H. (2012). Cross-language identification of long-term average speech spectra in Korean and English: Toward a better understanding of the quantitative difference between two languages. Ear and Hearing, 33(3), 441-443.

Overseas Korean Education Promotion Foundation. (2006). For Students of Hangul School Learning Korean with Fairy Tales. (pp. 12-75). Seoul: Overseas Korean Education Promotion Foundation.

Pearsons, K. S., Bennett, R. L., \& Fidell, S. (1977). Speech Levels in Various Noise Environments. EPA/600/1-77/025 (NTIS PB270053). Washington, D.C.: United States Environmental Protection Agency.

Scheaffer, R. L., Mendenhall, W. III., Ott, R. L., \& Gerow, K G. (2012). Elementary Survey Sampling. (7th ed.). Boston, MA: Brooks/Cole.

Scollie, S., Seewald, R., Cornelisse, L., Moodie, S., Bagatto, M., Laurnagaray, D., et al. (2005). The desired sensation level multistage input/output algorithm. Trends in Amplification, 9(4), 159-197.

Yun Y. S. (2007). Korean-voice handicap index(K-VHI): Validation of an original version and development of new version (Unpublished doctoral dissertation). Yonsei University, Seoul. 